\title{
Impact of Diabetes Mellitus on 1867 Acute Ischemic Stroke Patients. A Bergen NORSTROKE Study
}

\author{
Aliona $\mathrm{Nacu}^{1}$, Lars Thomassen ${ }^{2}$, Annette Fromm ${ }^{3}$, Anna Therese Bjerkreim ${ }^{4}$, Ulrike \\ Waje Andreassen ${ }^{5}$ and Halvor Naess ${ }^{6}$ \\ $1,2,3,4,5,6$ Department of Neurology, Haukeland University Hospital, N-5021 Bergen, Norway \\ $1,2,3,4,5,6$ Department of Clinical Medicine, University of Bergen, Post box 7804, N-5020 Bergen, \\ Norway \\ ${ }^{6}$ Centre for age-related medicine, Stavanger University Hospital, Post box 8100, N-4068 Stavanger, \\ Norway
}

Correspondence should be addressed to: Aliona Nacu; aliona.nacu@helse-bergen.no

Received date: 30 October 2013; Accepted date: 20 December 2013; published date: 9 July 2015

Academic Editor: Adrià G. Arboix

Copyright (C) 2015. Aliona Nacu, Lars Thomassen, Annette Fromm, Anna Therese Bjerkreim, Ulrike Waje Andreassen and Halvor Naess. Distributed under Creative Commons CC-BY 3.0

\begin{abstract}
Objective: Our aim was to compare the clinical characteristics including risk factors, comorbidities, short-term outcome and long-term mortality in acute ischemic stroke patients with or without diabetes mellitus. Methods: This study includes all consecutive patients with acute ischemic stroke admitted to the Stroke Unit, Department of Neurology, Haukeland University Hospital between February 2006 and January 2012. The National Institute of Health Stroke Scale (NIHSS) was used to assess stroke severity on admission. Short-term outcome was determined by the modified Rankin scale (mRS), NIHSS, and Barthel index on day 7 after stroke onset. First emergency readmission $<12$ months after discharge was registered. Survival state was obtained by consulting the official population registry. Results: In total, 1867 patients of which 283 (15\%) patients had diabetes mellitus. Relative frequency of diabetes mellitus according to age showed and inverse U-shape with highest frequency at 75-80 years for males, whereas the frequency was independent of age among females. More males than females had diabetes mellitus. Patients with diabetes mellitus more often had myocardial infarction, angina pectoris, hypertension (all $\mathrm{P}<.001$ ), and higher total risk factor burden $(\mathrm{P}<.001)$. Patients with diabetes mellitus had worse short-term outcome $(\mathrm{P}<0.001)$ and long-term mortality was increased. Patients with diabetes mellitus had more frequent first emergency readmission within 90 days $(\mathrm{P}=0.044)$. Conclusions: Stroke patients with diabetes mellitus have significantly more traditional risk factors. Short-term outcome and long-term mortality were worse. Relative frequencies of diabetes mellitus and age differed between males and females.
\end{abstract}

Key words: acute ischemic stroke, diabetes mellitus, risk factors, outcome

Cite this Article as: Aliona Nacu, Lars Thomassen, Annette Fromm, Anna Therese Bjerkreim, Ulrike Waje Andreassen and Halvor Naess (2015), "Impact of Diabetes Mellitus on 1867 Acute Ischemic Stroke Patients. A Bergen NORSTROKE Study", Journal of Research in Diabetes, Vol. 2015(2015), Article ID 112104, DOI: $10.5171 / 2015.112104$ 


\section{Introduction}

Stroke and diabetes mellitus (DM) are two of the leading causes of death worldwide. The prevalence of stroke in adult patients with DM is high and the risk of death is about twice that of people of similar age without DM (Department of Health and Human Services, 2011). DM increases the risk of stroke by two to six times and may be complicated by retinopathy, kidney disease and peripheral neuropathy, and increases the risk of atherosclerosis and cardiovascular diseases (CVD)(Department of Health and Human Services, 2011).Approximately $\quad 30 \%$ of stroke patients have DM (Reeves et al., 2010) and $16 \%$ of patients with DM have stroke (Department of Health and Human Services, 2011).

The combination of stroke and DM is associated with worse stroke-related outcome, high disability and stroke recurrence (Reeves et al., 2010), (Jia et al., 2011). Approximately $20 \%$ of patients with DM die from stroke (Phipps et al., 2012).

Our aim was to compare the clinical characteristics, including risk factors, comorbidities, complications, short-term outcome and long-term mortality in cohort of acute ischemic stroke patients with and without DM in Western Norway. We hypothesized that patients with DM have more risk factors (other than diabetes mellitus), worse neurological deficits on admission and worse short-term outcome in a Stroke unit with relatively high frequency of thrombolytic treatment.

\section{Methods}

All consecutive patients with acute ischemic stroke (the index stroke) admitted to the Stroke Unit, Department of Neurology, Haukeland University Hospital between February 2006 and January 2012 were prospectively registered in a database (The Bergen NORSTROKE Registry). Cerebral infarction was defined in accordance with the Baltimore-Washington Cooperative Young Stroke Study Criteria comprising neurological deficits lasting more than 24 hours because of ischemic lesions or transient ischemic attacks where computed tomography (CT) or magnetic resonance imaging (MRI) showed infarctions related to the clinical findings (Rohr et al., 1996). The National Institute of Health Stroke Scale (NIHSS) was used to assess stroke severity on admission. Shortterm outcome was defined by the modified Rankin scale (mRS) score on day 7 or at discharge, if discharged earlier. Leucoaraiosis was defined as presence of hypodense abnormalities surrounding the ventricles and in the deep white matter on MRI.

Work-up included ECG, Holter monitoring, duplex sonography of neck vessels, ecco cardiography and blood sample taken on admission. Body Mass Index (BMI) was calculated.

Isolated acute ischemic lesions on CT or MRI were defined as lacunar infarctions (LI) if $<1.5 \mathrm{~cm}$ and located subcortical or in the brainstem (Wessels et al., 2006). All other acute ischemic lesions were defined as none-lacunar infarction (NLI). NLI comprised subcortical and brainstem infarction $\geq 1.5 \mathrm{~cm}$, cortical infarction, mixed cortical and subcortical infarction and cerebellar infarction.

DM was considered present if diagnosed before the index stroke (patient on glucoselowering diet or medication) or during hospital stay (fasting plasma glucose $>7.7$ mmol/L). Current smoking was defined as smoking at least one cigarette per day. Hypertension was considered present if was diagnosed by a physician (previous diagnosis, current treatment, or values $\geq 160 / 95 \mathrm{~mm} \mathrm{Hg}$ ). Atrial fibrillation was considered present if there was history of chronic or paroxysmal atrial fibrillation confirmed by at least 1 ECG any time prior to stroke onset, or presence of atrial fibrillation during hospitalization.

Angina pectoris, myocardial infarction and peripheral artery disease were considered present if diagnosed by a physician any time before stroke onset or during hospital stay. Aetiology was determined by the Trial of Org 10172 in Acute Stroke Treatment classification (TOAST) and classified as large-artery atherosclerosis, cardioembolism, small vessel disease, other, and unknown (Adams et al., 1993). Clinical classification was based on the Oxford 
Community Stroke Project classification (OCSP) scale which includes lacunar syndrome (LACS), partial anterior circulation syndrome (PACS), total anterior circulation syndrome (TACS) and posterior circulation syndrome (POCS) (Bamford et al., 1991). OCSP has good inter-observer reliability (Lindley et al., 1993). A variable representing the sum of traditional risk factors (prior myocardial infarction, angina pectoris, peripheral artery disease, hypertension, smoking and atrial fibrillation) was generated. Tissue plasminogen activator ( tPA) was administered to eligible patients according to the SITS protocol (Wahlgren et al., 2007). In addition, tPA was administered in the 3-4.5 hour time-window and to patients $>80$ years based on a case by case evaluation. First emergency re-admission within one year after discharge was registered from the patient's medical chart. Early readmission was defined as readmission $<90$ days after discharge. Survival state was obtained by consulting the official population registry. The study was approved by the local Ethics committee.

\section{Statistics}

Chi-square, students t-test, MannWhitney's tests were used when appropriate. Logistic regression analyses with mRS scores $0-2$ versus $3-6$ as dependent variable were performed to analyze factors associated with short-term outcome. Logistic regression analyses with DM versus non-DM as dependent variable were performed to study risk factors associated with DM. Cox regression analyses were performed for long-term survival among patients alive 30 days after stroke onset. STATA 11.0 (Statacorp 4905 Lakeway Drive, College Station, Texas 77845 USA) was used for analyses.

\section{Results}

Of 1867 patients with acute ischemic stroke, 283 (15\%) patients had DM. The number of patients with undiagnosed DM prior to admission was 24 (1.3\%). Table 1 shows the demography of stroke patients with and without DM. More males than females had DM $(\mathrm{P}=.014)$ and patients with DM were older $(\mathrm{P}=.015)$ and had more often prior cerebral infarction $(\mathrm{P}=.014)$. In total, $44(16 \%)$ with diabetes mellitus and 267 (17\%) without diabetes mellitus received thrombolysis $(\mathrm{P}=.58)$.

Table 1: Demography of acute ischemic stroke patients with and without diabetes

\begin{tabular}{|l|c|c|c|}
\hline & Diabetes mellitus & No diabetes mellitus & P \\
\hline Total & $283(15)$ & $1584(85)$ & \\
\hline Male & $179(63)$ & $878(55)$ & .014 \\
\hline Female & $104(37)$ & $706(45)$ & \\
\hline Age & $72.6(12.6)$ & $70.3(15.2)$ & .015 \\
\hline Prior cerebral infarction & $57(20)$ & $228(15)$ & .014 \\
\hline Prior cerebral hemorrhage & $7(2.5)$ & $18(1.1)$ & .07 \\
\hline Prior TIA & $29(10)$ & $121(8)$ & .14 \\
\hline Prior myocardial infarction & $64(23)$ & $202(13)$ & $<.001$ \\
\hline Prior angina pectoris & $73(26)$ & $175(11)$ & $<.001$ \\
\hline Prior peripheral atherosclerosis & $30(11)$ & $104(7)$ & .014 \\
\hline
\end{tabular}

Aliona Nacu, Lars Thomassen, Annette Fromm, Anna Therese Bjerkreim, Ulrike Waje Andreassen and Halvor Naess (2015), Journal of Research in Diabetes, DOI: 10.5171/2015.112104 


\begin{tabular}{|l|c|c|c|}
\hline & Diabetes mellitus & No diabetes mellitus & P \\
\hline Prior hypertension & $199(71)$ & $757(48)$ & .001 \\
\hline Atrial fibrillation & $92(33)$ & $435(27)$ & .08 \\
\hline Migraine & $29(14)$ & $236(21)$ & .036 \\
\hline Prior depression & $49(24)$ & $246(21)$ & .001 \\
\hline Never smoker & $101(38)$ & $626(42)$ & .31 \\
\hline Stopped smoking & $112(42)$ & $463(31)$ & .93 \\
\hline Smoking & $52(20)$ & $404(27)$ & $<.001$ \\
\hline Home nursing & $40(14)$ & $173(11)$ & $887(57)$ \\
\hline Married & $158(57)$ & $441(29)$ & \\
\hline Employed & $42(15)$ & & \\
\hline
\end{tabular}

mellitusNumbers are presented as n (\%) unless specified; TIA = transient ischemic attack

Table 2: Clinical features of acute ischemic stroke patients with and without diabetes mellitus

\begin{tabular}{|c|c|c|c|}
\hline & Diabetes mellitus & No diabetes mellitus & $\mathrm{P}$ \\
\hline NIHSS on admission, median (IQR) & $4(2-10)$ & $4(1-8)$ & .06 \\
\hline Modified Rankin score median (IQR) & $2(1-4)$ & $2(1-4)$ & $<.001$ \\
\hline Systolic blood pressure on admission & $168(30)$ & $164(36)$ & .14 \\
\hline Modified Rankin score, mean & $2.6(1.7)$ & $2.2(1.6)$ & $<.001$ \\
\hline 30 days mortality & $25(8.8)$ & $117(7.4)$ & .40 \\
\hline OCSP & & & .59 \\
\hline LACS & $57(20)$ & $369(23)$ & \\
\hline TACS & $54(19)$ & $268(17)$ & \\
\hline PACS & $117(41)$ & $630(40)$ & \\
\hline POCS & $54(19)$ & $313(20)$ & \\
\hline \multicolumn{4}{|l|}{ TOAST } \\
\hline Athersclerosis & $43(15)$ & $181(11)$ & .07 \\
\hline Cardiac embolism & $92(33)$ & $510(32)$ & .92 \\
\hline Small vessel disease & $35(12)$ & $203(13)$ & .84 \\
\hline
\end{tabular}

Aliona Nacu, Lars Thomassen, Annette Fromm, Anna Therese Bjerkreim, Ulrike Waje Andreassen and Halvor Naess (2015), Journal of Research in Diabetes, DOI: 10.5171/2015.112104 


\begin{tabular}{|l|c|c|l|}
\hline & Diabetes mellitus & No diabetes mellitus & $P$ \\
\hline Other & $2(.7)$ & $48(3)$ & \\
\hline Unknown & $110(39)$ & $639(40)$ & .64 \\
\hline
\end{tabular}

Numbers are presented as n (\%) unless specified; NIHSS $=$ National Institutes of Health Stroke Scale; OCSP = Oxford Community Stroke Project classification; LACS = lacunar syndrome; PACS = partial anterior circulation syndrome; TACS $=$ total anterior circulation syndrome; POCS = posterior circulation syndrome; TOAST = Trial of Org 10172 in Acute Stroke Treatment

Table 3: In-hospital complications in acute ischemic stroke patients with and without diabetes mellitus

\begin{tabular}{|l|c|c|c|}
\hline & Diabetes mellitus & No diabetes mellitus & $\mathrm{P}$ \\
\hline Urinary retention & $103(36)$ & $433(27)$ & .002 \\
\hline Urinary incontinence & $50(21)$ & $211(16)$ & .09 \\
\hline Myocardial infarction & $7(2.5)$ & $24(1.5)$ & .25 \\
\hline Recurrent cerebral infarction & $1(.4)$ & $7(.4)$ & .83 \\
\hline Stroke in progression (NIHSS>=4) & $38(19)$ & $201(18)$ & .60 \\
\hline Pneumonia & $37(13)$ & $142(9)$ & .03 \\
\hline Urinary tract infection & $46(16)$ & $211(13)$ & .19 \\
\hline Epileptic seizures & $15(5)$ & $42(2.7)$ & .017 \\
\hline
\end{tabular}

Numbers are presented as n (\%) unless specified; NIHSS = National Institutes of Health Stroke Scale

Table 4: Imaging and blood analyses in acute ischemic stroke patients with and without diabetes mellitus

\begin{tabular}{|l|c|c|c|}
\hline & Diabetes mellitus & No diabetes mellitus & P \\
\hline Embolic infarction on MRI & $163(76)$ & $922(75)$ & .71 \\
\hline Lacunar infarction on MRI & $51(24)$ & $308(25)$ & \\
\hline Leucoaraiosis on MRI & $101(45)$ & $548(43)$ & .66 \\
\hline Blood analyses on admission & & & \\
\hline Glucose & $9.6(4.1)$ & $6.3(1.5)$ & $<.001$ \\
\hline CRP & $12.5(29)$ & $11.3(28)$ & .54 \\
\hline Creatinine & $89(44)$ & $83(30)$ & .002 \\
\hline D-dimer & $1.5(2.8)$ & $1.5(2.7)$ & .93 \\
\hline
\end{tabular}

Aliona Nacu, Lars Thomassen, Annette Fromm, Anna Therese Bjerkreim, Ulrike Waje Andreassen and Halvor Naess (2015), Journal of Research in Diabetes, DOI: 10.5171/2015.112104 


\begin{tabular}{|l|c|c|c|}
\hline & Diabetes mellitus & No diabetes mellitus & $P$ \\
\hline Fibrinogen & $4.0(1.1)$ & $3.8(1.7)$ & .09 \\
\hline Cholesterol & $4.9(1.4)$ & $5.5(1.3)$ & $<.001$ \\
\hline Thrombolysis & $44(16)$ & $267(17)$ & .58 \\
\hline
\end{tabular}

Numbers are presented as n (\%) unless specified; MRI = magnetic resonance imaging

Patients with DM had more traditional risk factors including hypertension, myocardial infarction and angina pectoris than patients without DM (1.8 versus 1.3 , $\mathrm{P}<.001)$. DM was the only known risk factor for acute ischemic stroke in $4.7 \%$ of the patients with DM. Smoking and cholesterol level were significant lower in DM patients $(\mathrm{P}=<.001)$ whereas creatinine was higher $(\mathrm{P}=.002)$. Statin prior to stroke onset was used by $46 \%$ with DM and $22 \%$ without DM $(\mathrm{P}<.001)$. The most common cardiovascular risk factor for both groups was hypertension. Patients with DM had significantly higher rates of myocardial infarction, angina pectoris, and hypertension (all $\mathrm{P}<.001$ ), peripheral atherosclerosis $(\mathrm{P}=.014)$ and migraine $(\mathrm{P}=$ .036). There was a weak correlation between BMI and DM $(r=.14, \mathrm{P}<.001)$.

The frequency of urinary retention $(\mathrm{P}=.002)$, pneumonia $(\mathrm{P}=.03)$, epileptic seizures $(\mathrm{P}=.017)$ in hospital were higher in the DM group.
There was a trend to more atherosclerosis according to TOAST criteria among patients with DM (P=.07). No differences were found in the distributions of OCSP subtypes.

Logistic regression with mRS score 0-2 versus 3-6 at day 7 as dependent variable showed that unfavorable functional outcome (mRS 3-6) was associated with DM after adjusting for confounders (Table 5). Including glucose level on admission as independent variable showed that glucose was associated with unfavorable outcome $(\mathrm{OR}=1.10, \mathrm{P}=.001)$ whereas $\mathrm{DM}$ was no longer associated with outcome $(P=.65)$. Logistic regression with or without DM as dependent variables showed that DM was associated with being male, not smoking, prior myocardial infarction, hypertension and more severe stroke (Table 6). There was no association between length of hospital stay and DM $(\mathrm{P}=.59)$.

Table 5: Logistic regression based on knowledge on admission with mRS score 3-6 versus 0-2 as dependent variable

\begin{tabular}{|l|c|c|c|}
\hline & Odds ratio & Confidence interval & $P$ \\
\hline Sex & .82 & $.64-1.06$ & .12 \\
\hline Age & 1.04 & $1.03-1.05$ & $<.001$ \\
\hline NIHSS score on admission & 1.30 & $1.26-1.34$ & $<.001$ \\
\hline Diabetes mellitus & 1.56 & $1.12-2.2$ & .008 \\
\hline
\end{tabular}

mRS = modified Rankin score; NIHSS = National Institutes of Health Stroke Scale 
Table 6: Logistic regression with diabetes mellitus versus not diabetes mellitus as dependent variable

\begin{tabular}{|l|c|c|c|}
\hline & Odds ratio & Confidence interval & P \\
\hline Male & 1.7 & $1.2-2.2$ & .001 \\
\hline Age & 1.0 & $.99-1.01$ & .58 \\
\hline Myocardial infarction & 1.7 & $1.2-2.4$ & .002 \\
\hline Hypertension & 2.5 & $1.9-3.4$ & $<.001$ \\
\hline Modified Rankin score & 1.2 & $1.06-1.3$ & .001 \\
\hline Smoking & .7 & $.5-.95$ & .02 \\
\hline
\end{tabular}

Among 30 days survivors, DM was associated with long term mortality (hazard ratio $1.5, \mathrm{P}=.007$ ) after adjusting for sex, age and NIHSS score on admission. In total, $47 \%$ of DM patients and $36 \%$ without DM patients experienced at least one emergency readmission $<1$ year after discharge $(\mathrm{P}=0.010)$. Early readmission ( $<90$ days) was more frequent among patients with DM $(24 \%$ versus $18 \%$,
$\mathrm{P}=0.044$ ) whereas there was no difference as to readmission 90-365 days after discharge $(\mathrm{P}=0.12)$. At 3 months after stroke onset 38 (13.4\%) of the patients with DM had died compared to 155 (9.8\%) non-DM patients $(\mathrm{P}=.06)$.

Figures 1 and 2 show the relative frequencies of DM in males and females according to age.

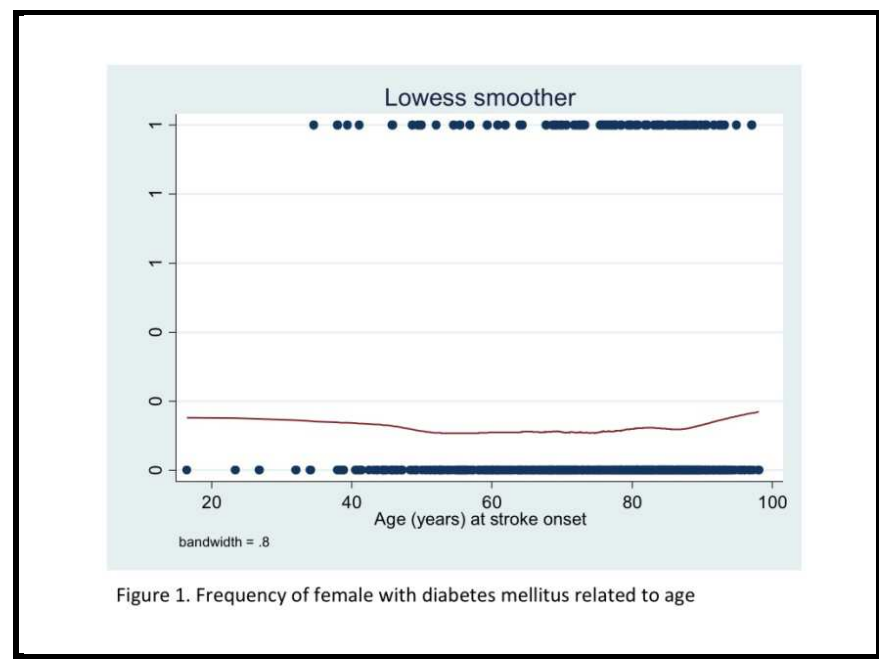

Aliona Nacu, Lars Thomassen, Annette Fromm, Anna Therese Bjerkreim, Ulrike Waje Andreassen and Halvor Naess (2015), Journal of Research in Diabetes, DOI: 10.5171/2015.112104 


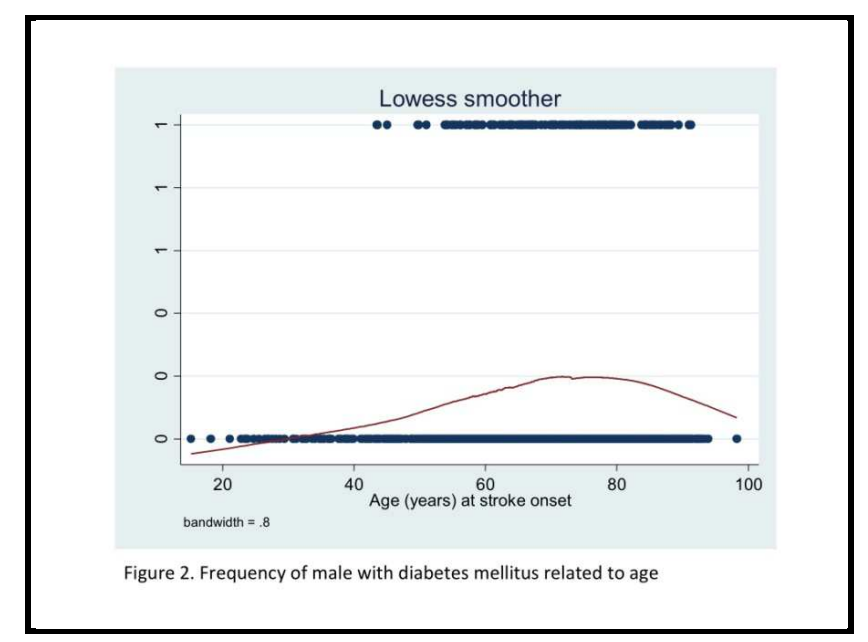

\section{Discussion}

Our study comprises a comprehensive comparison between ischemic stroke patients with and without diabetes mellitus. One important finding was that although diabetes mellitus was more frequent among old patients, assessing the sexes separately disclosed important differences. Among males the relative frequencies of diabetes mellitus increased with increasing age up to about 75-80 years and then declined. By contrast, among females the relative frequency of diabetes mellitus was constant irrespective of age interval. Other studies have disclosed conflicting results, finding that patients with diabetes mellitus are older (Megherbi et al., 2003) (Jorgensen et al., 1994), younger (Kissela et al., 2005) or no differences according to age (Karapanayiotides et al., 2004) (Zhang et al., 2012a).

Our study shows that patients with diabetes mellitus have more traditional risk factors than patients without diabetes mellitus. Thus, prior hypertension, myocardial infarction, angina pectoris and cerebral infarction analysed separately were significantly more frequent in the diabetes mellitus group. These results are compatible to findings in other studies (Reeves et al., 2010) (Harriott et al., 2013).

Smoking was significantly less frequent among patient with diabetes mellitus, even when adjusting for age. It is likely that patients with diabetes mellitus are less prone to smoking because they are aware of the relation between smoking and diabetic complications. One study found no differences in smoking frequencies between stroke patients with and without diabetes mellitus (Megherbi et al., 2003), but another study found frequencies in agreement with our study (Giorda et al., 2007). We have recently shown that recurrent vascular events and long term mortality are highly associated with the number of traditional risk factors in patients with cerebral infarction (Gjerde and Naess, 2013),(Putaala et al., 2010). Our study shows that the risk factor burden (other than diabetes mellitus) is especially high among patients with DM and cerebral infarction. This underlines the need for aggressive secondary preventive treatment among patients with diabetes mellitus. Physical activity, low fat, low carbohydrate diet, weight loss, moderation of alcohol, careful monitoring of diabetes, hypertension and others risk factors will reduce the severity and recurrence of stroke and improve quality of life (American Diabetes, 2012),(Hewitt et al., 2012).

There was no significant difference as to stroke severity on admission between patients with and without diabetes mellitus. However, short-term outcome as measured by the mRS was significantly worse among patients with diabetes mellitus even after adjusting for confounding factors including stroke severity on admission. A possible explanation is that ischemic brain tissue is more vulnerable in patients with diabetes mellitus. Including glucose on admission in

Aliona Nacu, Lars Thomassen, Annette Fromm, Anna Therese Bjerkreim, Ulrike Waje Andreassen and Halvor Naess (2015), Journal of Research in Diabetes, DOI: 10.5171/2015.112104 
the multivariate analysis showed that short term-outcome was associated with hyperglycemia whereas now diabetes mellitus was no longer associated with outcome. This is in line with other studies that found hyperglycemia is associated with poor outcome (Bruno et al., 1999). Hyperglycemia on admission is an important determinant of infarct volume expansion, even in patients with good collateral circulation (Kimura et al., 2011),(Shimoyama et al., 2013). Hyperglycemia induces progressive cerebrovascular changes during ischemia and affects hemodynamic recovery after reperfusion (Kawai et al., 1997). Others have reported that females with diabetes mellitus have poor prognosis (Arboix et al., 2006)

We found no differences in the distributions of ischemic stroke subtype based on the OCSP classification. This is also consistent with another study (Kiers et al., 1992). However, others have reported an association between diabetes and posterior circulation infarctions (Karapanayiotides et al., 2004) and/or lacunar infarctions (Megherbi et al., 2003),(Lees and Walters, 2005). Others have found that lacunar infarctions have better functional prognosis than embolic infarction among patients with diabetes mellitus (Arboix et al., 2001). It remains an open question whether diabetes mellitus causes small vessel disease or not.

We found that patients with diabetes mellitus had more complications than patients without diabetes mellitus during the hospital stay. Urinary retention, pneumonia and epileptic seizures were significantly more frequent among our patients with diabetes mellitus. Urinary retention was found as high as $44 \%$ in another study (Kong and Young, 2000). The authors suggested diabetic cystopathy as cause, and they believed retention to be a transient phenomenon that should be followed by postvoid residual screening in all patients immediately after stroke (Kong and Young, 2000). Another study reported high frequency of pneumonia in older patients with stroke and diabetes (30\%). Older age, higher NIHSS on admission and dysphagia may predict the occurrence of pneumonia on stroke onset (Zhang et al., 2012b). Hyperglycemia may be a significant factor that induces epileptic seizures in some patients (Arboix A, 1996), (Azra Alajbegovic, 2002). We found that patients with ischemic stroke and diabetes mellitus had higher frequencies of first emergency readmission, which is supported by another study (Sun and Toh, 2009). Main diagnoses for patients readmitted within 3 months were cardiovascular disorders, stroke related causes and infections.

Diabetes mellitus was not associated with mortality within the first 30 days after stroke onset among our patients. By contrast, another study found increased early mortality in patients with stroke and diabetes mellitus (Kiers et al., 1992). We found that among 30 days survivors long term mortality was associated with diabetes mellitus after adjusting for confounders. Another large study found that diabetic patients did not have significantly higher mortality rate at 60 days and 1 year after stroke onset, but long term mortality was higher among stroke patients with diabetes mellitus (Kamalesh et al., 2008).

One of the strengths of this study is the inclusion of patients living in a well-defined geographical region. Admission threshold is low for patients with possible acute stroke. This indicates that few cases escaped our attention. Another of the strengths of this study is access to the mortality data from the official population registry. All deaths in Norway are reported. A limitation of the study is that the cause of death was unknown. Another limitation is that we do not know the functional outcome 3 months after stroke onset.

\section{Conclusion}

Patients with diabetes mellitus and cerebral infarction have poorer short-term functional outcome, more complications, more early readmissions and higher longterm mortality than patients with cerebral infarction and without diabetes mellitus. Relative frequencies of diabetes mellitus

Aliona Nacu, Lars Thomassen, Annette Fromm, Anna Therese Bjerkreim, Ulrike Waje Andreassen and Halvor Naess (2015), Journal of Research in Diabetes, DOI: 10.5171/2015.112104 
and age differed between males and females.

\section{Acknowledgments}

The authors thank research nurse Maren Inselseth for her excellent work and assistance with data registration.

\section{References}

1. Adams, HP Jr, Bendixen, BH., Kappelle, LJ., Biller, J., Love, BB., Gordon, DL. and Marsh EE 3rd. (1993), 'Classification of subtype of acute ischemic stroke. Definitions for use in a multicenter clinical trial. TOAST. Trial of Org 10172 in Acute Stroke Treatment,' Stroke, 24, 35-41.

2. American Diabetes Association. (2012), 'Standards of medical care in diabetes-2012,' Diabetes Care, 35 (1), S11-63.

3. Arboix, A., Comes, E., Massons. J., García, L. and Oliveres M. (1996), 'Relevance of early seizures for inhospital mortality in acute cerebrovascular disease,' Neurology, 47, 1429-1435.

4. Arboix, A., Milian, M., Oliveres, M., García-Eroles, L. and Massons, J. (2006), 'Impact of Female Gender on Prognosis in Type 2 Diabetic Patients with Ischemic Stroke,' European Neurology, 56, 6-12.

5. Arboix, A., Paladilla, I., Massons J., García-Eroles, L., Comes, E., and Targa, C. (2001), ' Clinical study of 222 patients with pure motor stroke,' Journal of Neurology, Neurosurgery, Psychiatry, 71 (2), 239-242

6. Aljbegovic, A., Metelko, Z., Aljbegovic, S., Kantardzic, D., Bratic, M., Suljic, E., Hrnjica, M. and

7. Resić H. (2002), 'Correlation between early and late epileptic seizures and diabetes mellitus during and after stroke,' Diabetologia Croatica, 31-3, 173-177.

8. Bamford, J., Sandercock, P., Dennis, M., Burn, J. and Warlow, C. (1991), 'Classification and natural history of clinically identifiable subtypes of cerebral infarction,' Lancet, 337 (8756), 1521-6.
9. Bruno, A., Biller, J., Adams, HP Jr., Clarke, WR., Woolson, RF., Williams, LS. and Hansen, MD. (1999), 'Acute blood glucose level and outcome from ischemic stroke. Trial of ORG 10172 in Acute Stroke Treatment (TOAST) Investigators,' Neurology, 52 (2), 280-4.

10. Centers for Disease Control and Prevention. (2011), 'National diabetes fact sheet: national estimates and general information on diabetes and prediabetes in the United States,' Department of Health and Human Services CfDCaP, editor. Atlanta: 2011. p. GA2011.

11. Giorda, CB., Avogaro, A., Maggini, M., Lombardo, F., Mannucci, E., Turco, S., Alegiani, SS., Raschetti, R., Velussi, M., Ferrannini, E. and DAI Study Group. (2007), 'Incidence and risk factors for stroke in type 2 diabetic patients: the DAI study,' Stroke, 38 (4), 1154-60.

12. Gjerde, G. and Naess, H. (2013), 'Risk factor burden predicts long-term mortality after cerebral infarction,' Acta Neurologica Scandinavica, 129 (3), 173-7.

13. Harriott, AM., Dueker, N., Cheng, YC., Ryan, KA., O'Connell, JR., Stine, OC., McArdle, PF., Wozniak, MA., Stern, BJ., Mitchell, BD., Kittner, SJ. and Cole, JW. (2013), 'Polymorphisms in migraineassociated gene, and ischemic stroke risk in a biracial population: the genetics of early onset stroke study,' Springerplus, 2 (1), 46.

14. Hewitt, J., Castilla, Guerra L., Fernández-Moreno, Mdel C. and Sierra, C. (2012),' Diabetes and stroke prevention: a review,' Stroke Res Treat, 2012, 673187. 15. Jia, Q., Zhao, X., Wang, C., Wang, Y., Yan, Y., Li, H., Zhong, L., Liu, L., Zheng, H., Zhou, Y. and Wang, Y. (2011), 'Diabetes and poor outcomes within 6 months after acute ischemic stroke: the China National Stroke Registry,' Stroke, 42 (10), 2758-62.

16. Jørgensen, HS., Nakayama, H., Raaschou, HO. and Olsen, TS. (1994), 'Effect of blood pressure and diabetes on stroke in progression,' Lancet, 344 (8916), 156-9. 
17. Kamalesh, M., Shen, J. and Eckert, GJ. (2008), 'Long term postischemic stroke mortality in diabetes: a veteran cohort analysis,' Stroke, 39 (10), 2727-31.

18. Karapanayiotides, T., PiechowskiJozwiak, B., van Melle, G., Bogousslavsky, J. and Devuyst, G. (2004), 'Stroke patterns, etiology, and prognosis in patients with diabetes mellitus,' Neurology, 62 (9), 155862.

19. Kawai, N., Keep, RF. and Betz, AL. (1997), 'Hyperglycemia and the vascular effects of cerebral ischemia,' Stroke, 28 (1), 149-54.

20. Kiers, L., Davis, SM., Larkins, R., Hopper, J., Tress, B., Rossiter, SC., Carlin, J. and Ratnaike. S. (1992), 'Stroke topography and outcome in relation to hyperglycaemia and diabetes,' Journal of Neurology, Neurosurgery \& Psychiatry, 55 (4), 263-70.

21. Kimura, K., Sakamoto, Y., Iguchi, Y., Shibazaki, K., Aoki, J., Sakai, K. and Uemura, J. (2011), 'Admission hyperglycemia and serial infarct volume after t-PA therapy in patients with and without early recanalization,' Journal of Neurological Sciences, 307 (1-2), 55-9.

22. Kissela, BM., Khoury, J., Kleindorfer, D., Woo, D., Schneider, A., Alwell, K., Miller, R., Ewing, I., Moomaw, CJ., Szaflarski, JP., Gebel, J., Shukla, R. and Broderick, JP. (2005), 'Epidemiology of ischemic stroke in patients with diabetes: the greater Cincinnati/Northern Kentucky Stroke Study,' Diabetes Care, 28 (2), 355-9.

23. Kong, KH. and Young, S. (2000). Incidence and outcome of poststroke urinary retention: a prospective study,' Archives of Physical Medicine and Rehabilitation, 81 (11), 1464-7.

24. Lees, KR. and Walters, MR. (2005), 'Acute stroke and diabetes,' Cerebrovascular Diseases, 20 Suppl 1, 9-14.

25. Lindley, RI., Warlow, CP., Wardlaw, JM., Dennis, MS., Slattery, J. and Sandercock, PA.
26. (1993), 'Interobserver reliability of a clinical classification of acute cerebral infarction,' Stroke, 24 (12), 1801-4.

27. Megherbi, SE., Milan, C., Minier, D., Couvreur, G., Osseby, GV., Tilling, K, Di Carlo, A., Inzitari, D., Wolfe, CD., Moreau, T., Giroud, M. and European BIOMED Study of Stroke Care Group. (2003), 'Association between diabetes and stroke subtype on survival and functional outcome 3 months after stroke: data from the European BIOMED Stroke Project,' Stroke, 34 (3), 688-94.

28. Phipps, MS., Jastreboff, AM., Furie, K. and Kernan, WN. (2012), 'The diagnosis and management of cerebrovascular disease in diabetes,' Current Diabetes Reports, 12 (3), 314-23.

29. Putaala, J., Haapaniemi, E., Metso, AJ., Metso, TM., Artto, V., Kaste, M. and Tatlisumak, T. (2010), 'Recurrent ischemic events in young adults after first-ever ischemic stroke,' Annals of Neurology, 68 (5), 661-71.

30. Reeves, MJ., Vaidya, RS., Fonarow, GC., Liang, L., Smith, EE., Matulonis, R., Olson, DM., Schwamm LH., Get With The Guidelines Steering Committee and Hospitals. (2010), 'Quality of care and outcomes in patients with diabetes hospitalized with ischemic stroke: findings from Get With the Guidelines-Stroke,' Stroke, 41 (5), e409-17.

31. Rohr, J., Kittner, S., Feeser, B., Hebel, JR., Whyte, MG., Weinstein, A., Kanarak, N., Buchholz, D., Earley, C., Johnson, C., Macko, R., Price, T., Sloan, M., Stern, B., Wityk, R., Wozniak, M. and Sherwin, R. (1996), 'Traditional risk factors and ischemic stroke in young adults: the BaltimoreWashington Cooperative Young Stroke Study,' Archives of Neurology, 53 (7), 603-7.

32. Shimoyama, T., Shibazaki, K., Kimura, K., Uemura, J., Shiromoto, T., Watanabe, M., Inoue, T., Iguchi, Y. and Mochio, S. (2013), 'Admission hyperglycemia causes infarct volume expansion in patients with ICA or MCA occlusion: association of collateral grade on conventional angiography,'

Aliona Nacu, Lars Thomassen, Annette Fromm, Anna Therese Bjerkreim, Ulrike Waje Andreassen and Halvor Naess (2015), Journal of Research in Diabetes, DOI: 10.5171/2015.112104 
European Journal of Neurology, 20 (1), 10916.

33. Sun, Y. and Toh, MP. (2009), 'Impact of diabetes mellitus (DM) on the health-care utilization and clinical outcomes of patients with stroke in Singapore,' Value Health, 12 Suppl 3, S101-5.

34. Wahlgren, N., Ahmed, N., Dávalos, A., Ford, GA., Grond, M., Hacke, W., Hennerici, MG., Kaste, M., Kuelkens, S., Larrue, V., Lees, KR., Roine, RO., Soinne, L., Toni, D., Vanhooren, G. and SITS-MOST investigators. (2007), 'Thrombolysis with alteplase for acute ischaemic stroke in the Safe Implementation of Thrombolysis in Stroke-Monitoring Study (SITS-MOST): an observational study,' Lancet, 369 (9558), 275-82.
35. Wessels, T., Wessels, C., Ellsiepen, A., Reuter, I., Trittmacher, S., Stolz, E. and Jauss, M. (2006), 'Contribution of diffusionweighted imaging in determination of stroke etiology,' AJNR American Journal of Neuroradiology, 27 (1), 35-9.

36. Zhang, B., Gao, C., Hou, Q., Yin, J., Xie, L., $\mathrm{Pu}, \mathrm{S}$., Yi, Y. and Gao, Q. (2012), 'The potent different risk factors for cerebral infarction in young patients with and without type 2 diabetes: subanalysis of the Young Cerebral Infarction Study (YCIS),' Atherosclerosis, 221 (1), 215-20.

37. Zhang, X., Wang, F., Zhang, Y. and Ge, Z. (2012), 'Risk factors for developing pneumonia in patients with diabetes mellitus following acute ischaemic stroke,' Journal of International Medical Research, 40 (5), 1860-5. 